\title{
IMPROVING THE UTILIZATION OF TELLERS USING SIMULATION AT XYZ BANK
}

\author{
Nova Indah Saragih ${ }^{1 *}$, Muhammad Vighi Farakhan ${ }^{1}$, Sugia Ramdani Suganda1 ${ }^{1}$, Kusuma Fiqhy Kamalia ${ }^{1}$ \\ Department of Industrial Engineering ${ }^{1}$ \\ Widyatama University, Bandung, Indonesia \\ nova.indah@widyatama.ac.id
}

\begin{abstract}
Simulation is one of the techniques of operations research and management science that is most used widely. The goal of simulation is to estimate the performance measures of the evaluated system using computers. This paper provides the simulation of tellers to estimate and then improve its performance measure which is the utilization. The initial utilization of XYZ Bank is $24.13 \%$ on average. Two scenario are conducted to improve the utilization. Scenario 1 improves the utilization by $32.26 \%$ on average and scenario 2 improves the utilization by $47.84 \%$ on average. This paper suggests XYZ Bank to apply scenario 2 that can improve the utilization by $23.72 \%$.
\end{abstract}

Keywords: simulation, tellers, utilization

\section{INTRODUCTION}

According to Law and Kelton (1991), simulation is one of the techniques of operations research and management science that is most used widely. Simulation is used in complex systems which the models can not be evaluated analytically. The goal of simulation is to estimate the performance measures of the evaluated system using computers (Taha, 2007). This paper provides the simulation of tellers to estimate and then improve its performance measure which is the utilization. The simulation that is built in this paper adopts the methodology of Law and Kelton (1991).

There are four tellers that are available in the XYZ Bank. The conceptual model of XYZ Bank is given in Figure 1. Customers arrive at the bank and they queue to get the service. The customers are served based on FCFS (first come first served) rule and the availability of the tellers. After the customers are served by the tellers, they leave the bank.

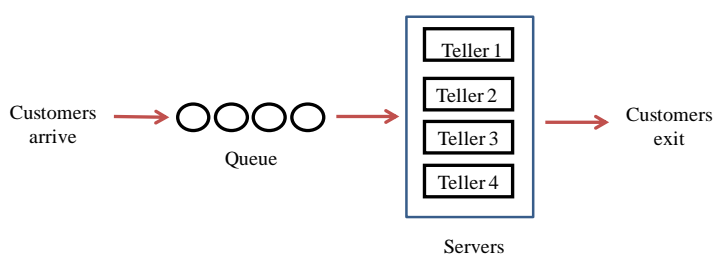

Figure 1. The conceptual model of XYZ Bank

\section{Methodology}

As it was mentioned previously, this paper adopts the methodology of Law and Kelton (1991) to build the simulation. The flow chart to build the simulation can be seen in Figure 2.

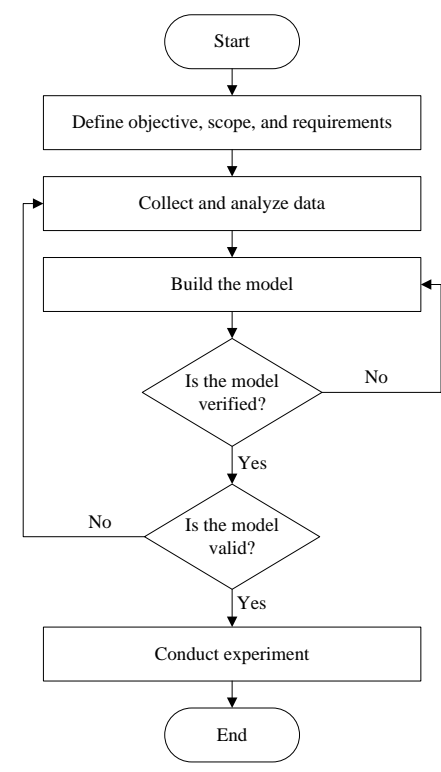

Figure 2. The flow chart of the simulation 


\section{Simulation Model}

\section{1 Data}

Based on Figure 1, it can be known data needed to build the simulation. They are interarrival time of the customers, service time of Teller 1, Teller 2, Teller 3, and Teller 4. The distribution of all the data is given in Table 1.

Table 1. The distribution of the data used

\begin{tabular}{cccc}
\hline \hline Data & Activity Time & $\begin{array}{c}\text { Activity } \\
\text { Resource }\end{array}$ & $\begin{array}{c}\text { Next } \\
\text { Location }\end{array}$ \\
\hline \hline Interarrival time & E(2.04) min & None & Teller 1 \\
\cline { 4 - 4 } & Teller 2 \\
\hline \hline & Teller 3 \\
\hline $\begin{array}{c}\text { Service time of } \\
\text { Teller 1 }\end{array}$ & $\begin{array}{c}\mathrm{L}(1.05,0.843) \\
\text { min }\end{array}$ & Teller 1 & Exit \\
\hline \hline $\begin{array}{c}\text { Service time of } \\
\text { Teller 2 }\end{array}$ & $\begin{array}{c}\mathrm{E}(6.99) \text { min } \\
\text { Teller 4 }\end{array}$ & Teller 2 & Exit \\
\hline \hline $\begin{array}{c}\text { Service time of } \\
\text { Teller 3 }\end{array}$ & $\begin{array}{c}\mathrm{L}(1.49,0.603) \\
\text { min }\end{array}$ & Teller 3 & Exit \\
\hline \hline $\begin{array}{c}\text { Service time of } \\
\text { Teller 4 }\end{array}$ & $\begin{array}{c}\mathrm{L}(1.21,0.8) \\
\text { min }\end{array}$ & Teller 4 & Exit \\
\hline \hline
\end{tabular}

In Figure 3, the result of goodness of fit test for interarrival time of the customers is given.

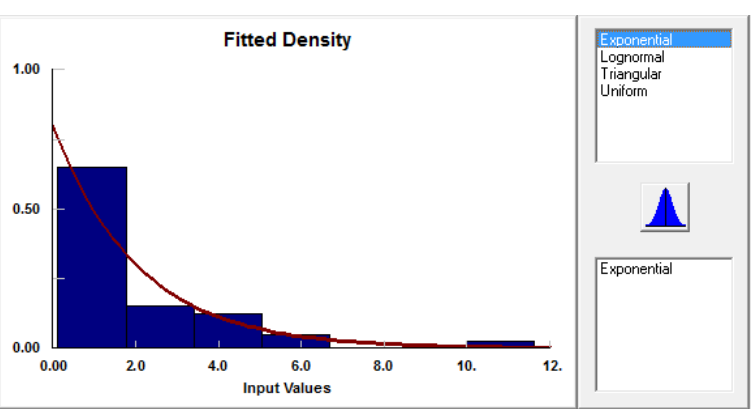

Figure 3. The result of goodness of fit test for interarrival time

The result of goodness of fit test for service time of Teller 1 is given in Figure 4.

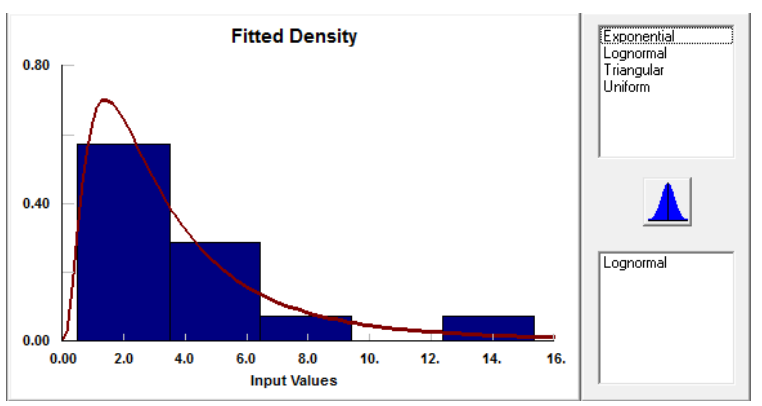

Figure 4. The result of goodness of fit test for service time of Teller 1

The result of goodness of fit test for service time of Teller 2 is given in Figure 5.

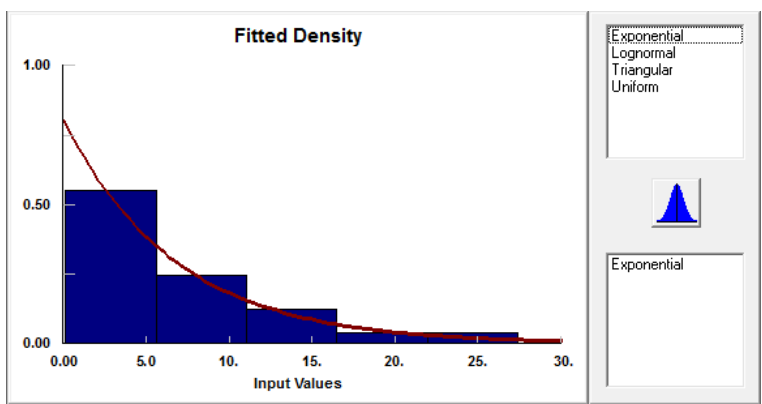

Figure 5. The result of goodness of fit test for service time of Teller 2

The result of goodness of fit test for service time of Teller 3 is given in Figure 6 .

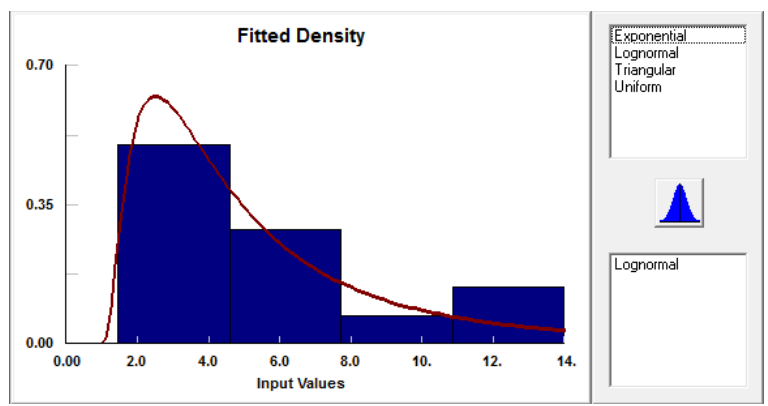

Figure 6. The result of goodness of fit test for service time of Teller 3

The result of goodness of fit test for service time of Teller 4 is given in Figure 7. 


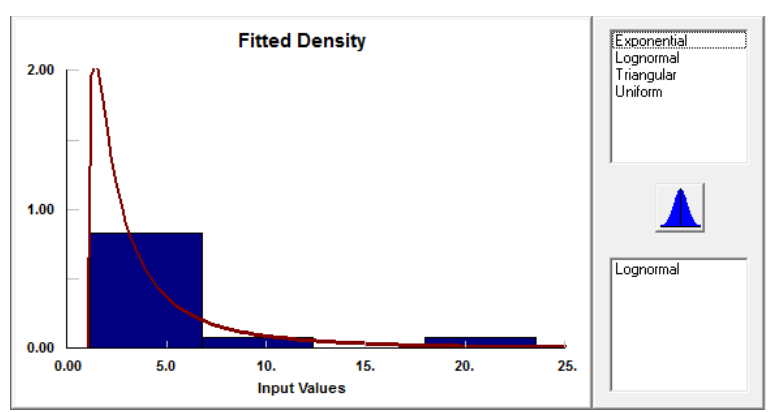

Figure 7. The result of goodness of fit test for service time of Teller 4

\section{III.2 Verification and Validation}

Verification is performed to assess whether the model (computer model) operates correctly (Altiok and Melamed, 2007). After performing verification for simulation model in this paper, it concludes that the simulation model is verified.

The accuracy of the simulation model to represent the real system is known as validation (Law and Kelton, 1991). Hypothesis testing is used to validate the simulation model. The result of the simulation model in the terms of number of customers exiting is given in Table 2.

Table 2. Simulation output

\begin{tabular}{cc}
\hline \hline Replication & Number of customers exiting \\
\hline \hline 1 & 239 \\
\hline \hline 3 & 225 \\
\hline \hline 4 & 234 \\
\hline \hline 5 & 245 \\
\hline \hline 6 & 220 \\
\hline \hline 7 & 237 \\
\hline \hline 9 & 225 \\
\hline \hline 9 & 247 \\
\hline \hline Mean & 213 \\
\hline \hline $\begin{array}{c}\text { Standard } \\
\text { deviation }\end{array}$ & 267 \\
\hline \hline Variance & 235.2 \\
\hline \hline
\end{tabular}

Meanwhile, from collected data, the number of customers exiting for ten days of observation is given in Table 3.

Table 3. Data of real system

\begin{tabular}{cc}
\hline \hline Day & Number of customers exiting \\
\hline \hline 1 & 239 \\
\hline \hline 3 & 248 \\
\hline \hline 4 & 223 \\
\hline \hline 5 & 259 \\
\hline \hline 6 & 243 \\
\hline \hline 7 & 241 \\
\hline \hline 9 & 236 \\
\hline \hline 9 & 238 \\
\hline \hline & 228 \\
\hline \hline $\begin{array}{c}\text { Standard } \\
\text { Meviation }\end{array}$ & 240 \\
\hline \hline $\begin{array}{c}\text { Variance } \\
10\end{array}$ & 239.5 \\
\hline \hline
\end{tabular}

Hypothesis testing used is confidence interval on the difference in means where $\sigma_{1}^{2} \neq \sigma_{2}^{2}$ (Montgomery and Runger, 2003). The hypothesis is given as follow.

$$
\begin{aligned}
& H_{0}: \mu_{1}-\mu_{2}=0 \\
& H_{1}: \mu_{1}-\mu_{2} \neq 0
\end{aligned}
$$

Confidence interval on the difference in means is as follow.

$$
\begin{aligned}
& \left(\overline{\mathrm{x}}_{1}-\overline{\mathrm{x}}_{2}\right)-t_{\alpha / 2, W} \sqrt{\frac{s_{1}^{2}}{n_{1}}+\frac{s_{2}^{2}}{n_{2}}} \leq \mu_{1}-\mu_{2} \leq\left(\overline{\mathrm{x}}_{1}-\right. \\
& \left.\overline{\mathrm{x}}_{2}\right)+t_{\alpha / 2, W} \sqrt{\frac{s_{1}^{2}}{n_{1}}+\frac{s_{2}^{2}}{n_{2}}}
\end{aligned}
$$

Degree of freedom (v) is given as follow.

Nova Indah Saragih, Muhammad Vighi Farakhan, Sugia Ramdani 


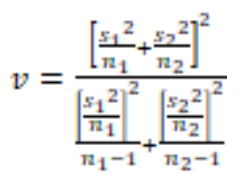

For $\alpha=5 \%$, the conclusion is do not reject $H_{0}$ and states that the model is valid.

\section{III.3 Number of replications}

The method used to determine the number of replications needed $(n)$ is relative error method that is given as follow.

$$
n=\left[\frac{\left(z_{m f_{2}}\right) s}{\left(\frac{\pi v}{1+v a}\right)}\right]^{2}
$$

For the evaluated system, the data are given in Table 2. For $\alpha=5 \%$ and $r e=5 \%$, the number of replications needed is 7 replications.

\section{DESIGN OF EXPERIMENTS}

Result of the initial simulation in the terms of the utilization can be seen in Table 4. As it was mentioned before, this paper tries to estimate and then improve the utilization of the tellers.

Table 4. The utilization of the tellers from initial simulation

\begin{tabular}{cr}
\hline \hline Teller & Utilization (\%) \\
\hline \hline Teller 1 & 34.67 \\
\hline \hline Teller 2 & 47.34 \\
\hline \hline Teller 3 & 10.71 \\
\hline \hline Teller 4 & 3.78 \\
\hline \hline & Average \\
\hline \hline
\end{tabular}

There are two scenarios developed to improve the utilization. Scenario 1 is removing Teller 4 and the result of scenario 1 is given in Table 5 .
Table 5. The utilization of the tellers from scenario 1

\begin{tabular}{cc}
\hline \hline Teller & Utilization (\%) \\
\hline \hline Teller 1 & 36.08 \\
\hline \hline Teller 2 & 47.64 \\
\hline \hline Teller 3 & 13.07 \\
\hline \hline Average & 32.26 \\
\hline \hline
\end{tabular}

Scenario 2 is removing Teller 3. The result of scenario 2 can be seen in Table 6 .

Table 6. The utilization of the tellers from scenario 2

\begin{tabular}{cc}
\hline \hline Teller & Utilization (\%) \\
\hline \hline Teller 1 & 42.93 \\
\hline \hline Teller 2 & 52.75 \\
\hline \hline Average & 47.84 \\
\hline \hline
\end{tabular}

\section{Analysis Of COMParing System}

Number of customers exiting for initial, scenario 1 , and scenario 2 is given in Table 7 .

Table 7. Number of customers exiting for intial, scenario 1, and scenario 2

\begin{tabular}{cccc}
\hline \hline Replication & Initial & Scenario 1 & \multicolumn{2}{c}{ Scenario 2 } \\
\hline \hline 1 & 239 & 243 & 251 \\
\hline 2 & 225 & 227 & 240 \\
\hline \hline 3 & 234 & 234 & 219 \\
\hline \hline 4 & 245 & 246 & 260 \\
\hline \hline 5 & 220 & 229 & 207 \\
\hline \hline 6 & 237 & 224 & 224 \\
\hline \hline 7 & 225 & 223 & 245 \\
\hline \hline
\end{tabular}

Nova Indah Saragih, Muhammad Vighi Farakhan, Sugia Ramdani 


\begin{tabular}{rrrr}
\hline \hline Replication & Initial & Scenario 1 & Scenario 2 \\
\hline \hline Total & 1625 & 1626 & 1646 \\
\hline \hline Mean & 232.143 & 232.286 & 235.143 \\
\hline \hline
\end{tabular}

Since there are 3 populations and single experiment, the hypothesis testing used is one-way Analysis of Variance or one-way ANOVA (Walpole et al., 2007).

The hypothesis is given as follow.

$$
\begin{aligned}
& H_{0}: \tau_{1}=\tau_{2}=\tau_{a}=0 \\
& H_{1}: \tau_{i} \neq 0 \text { for at least one } i
\end{aligned}
$$

For $\alpha=5 \%$, the conclusion is do not reject $H_{0}$ and states that one population is not significantly different than the others.

\section{Vi. Conclusions}

This paper estimates and improves the utilization of tellers at XYZ Bank using simulation. As it can be seen in Figure 8, initial utilization of XYZ Bank is $24.13 \%$ on average. Two scenario are conducted to improve the utilization. Scenario 1 improves the utilization by $32.26 \%$ on average and scenario 2 improves the utilization by $47.84 \%$ on average.

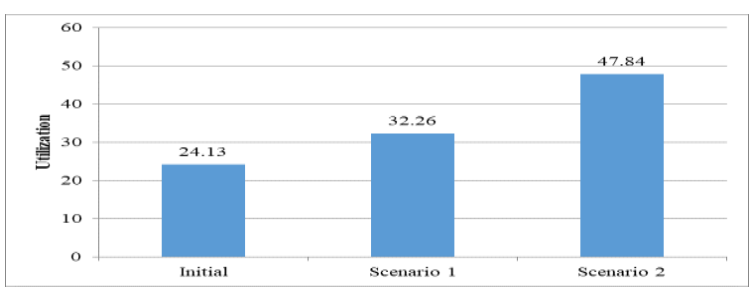

Figure 8. Improvement of the utilization

This paper suggests XYZ Bank to apply scenario 2 that can improve the utilization from $24.13 \%$ to $47.84 \%$. There is an improvement by $23.72 \%$. The number of tellers also decreases from 4 tellers to 2 tellers which means the cost also decreases.

\section{REFERENCES}

Altiok, T. and Melamed, B. 2007. Simulation Modeling and Analysis with Arena. Elsevier, Inc.

Law, A. M. and Kelton, W. D. 1991. Simulation Modeling And Analysis. McGraw-Hill, Inc.

Montgomery, D.C. and Runger, G. C. 2003. Applied Statistics and Probability for Engineers. John Wiley \& Sons, Inc.

Taha, A. H. 2007. Operations Research: An Introduction. Prentice Hall Education.

Walpole, R. E., Myers, R. H., Myers, S. L., and Ye, K. 2007. Probability \& Statistics for Engineers \& Scientists. Pearson Education, Inc. 